\title{
ORTHOPTERA NOVA ACREANA (Tettigoniidae)
}

\author{
S. DE TOLedo Piza JR. \\ Escola Superior de Agricultura "Luiz de Queiroz \\ Universidade de São Paulo - P I R A C I C A B A
}

\section{RESUMO}

\begin{abstract}
Do Prof Amilton Ferreira, da Faculdade de Filosofia de Rio Ciaro recebi, faz pouco tempo, pequeno lote de Tettigoniideos, para determinação. Desse material, estudado citologicamente, por aquele professor, separei cinco espécies novas para a ciência, duas das quais foram consideradas como tipos de novos gêneros.

O material foi coligido no Território do Acre. por Arnaldo Zaha, no mês de outubro de 1972 e doado pelo Prof. Amilton Ferreira ao Departamento de Zoologia da «Luiz de Queiroz», em cujas coleções foi incorporado. A ambos, os agradecimentos do autor.
\end{abstract}

Seguem-se as descrições

\section{PHANEROPTERINAE}

\section{Acrephyllum g. n.}

Vertex modice rotundatus, fastigio triangulari, superne sulcato et obsolete tuberculato, apice truncato cum fastigio frontis contiguo. Oculi rotundati. Frons convexa, sub oculos utrinque compressa. Pronotum breve, puncturatum disco subplano, margine antico sinuoso, postico regulariter curvo, lobis deflexis rotundatim insertis, altioribus quam longioribus, antice rectis, postice rotundatis, inferne sinuosis. Elytra longa, parallela apice rotundata, membranosa, hyalina, nítida, venis radialibus post medium disjunctis, irregulariter ramosis, ramis leniter expressis irregulariter divisis, margines elytrorum attingentibus. Alae extremitatem elytrorum superantes, tarsos posticos attingentia. Mesosternum lobis acutis, matasternum rotundatis. Femora I et II superne et inferne rotundata, inermia. Femora III gracilia, basi compressa, superne rotundata, inferne sulcata et spinis minimis utrinque armatae. Tibiae omnes superne rotundatae, I inermes, II spinis intus tantum, III utrinque armata. Segmentum anale truncatum. Cerci maris teretes, graciles, paulo curvi, basi modice incrassati. Lamina subgenitalis in medio carinata, margine postico rotundatim emarginato, stylis parvis instructa.

0 nome do gênero refere-se à pátria do inseto, Acre. 
O presente gênero, pelas tíbias anteriores e médias arredondadas encima e pelos fêmures anteriores e médios não sulcados embaixo aproxima-se de Anaulacomera Stal, do qual se distingue pela estrutura dos élitros e pela lâmina subgenital armada de estilos bem desenvolvidos.

Tipo, a espécie seguinte:

\section{Acrephyllum irregulare sp.}

- Viridis. Characteribus generis. Vertex parce minute puncturatus. Elytra margine postico linea lutea a extremitate areae strindulatoriae usque ad apicem ornata. Pedes graciles, fomoribus posticis basi paulo ampliatis.

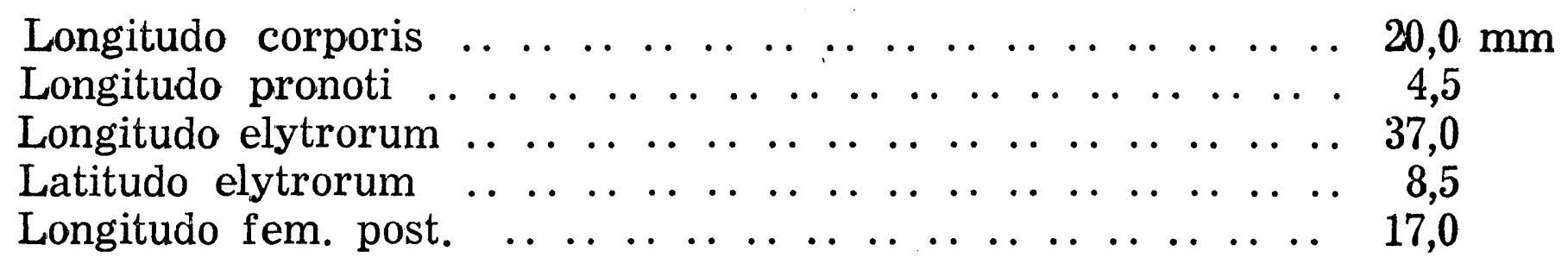

Tipo: um macho no Depart. de Zoologia da ESALQ.

Pátria: Cruzeiro do Sul, Acre.

Col.: Arnaldo Zaha, 10-1-972.

Doador: Dr. Amilton Ferreira.

\section{Pararota g. n.}

Frons convexa, nitida, utrinque compressa. Oculi rotundati. Vertex convexiusculus, fastigio angusto, apice obtuso cum fastigio frontis haud contiguo, sulcato. Pronotum disco parallelo, subconvexo, margine antico subtruncato, postico rotundato, lobis deflexis perpendicularibus, aeque longis ac latis, rotundatim insertis. Elytra membranosa, parallela, extremitatem femorum posticorum valde superantia, apice rotundata, venis radialibus sinuosis, ad trientem apicalem disjunctis, ramo primo venae posticae in medio oriente, in medio, ramos duos parallelos versus marginem posticum emittente, hunc marginem prope extremitatem elytrorum attingentibus. Vena ulnaris antica vix sinuosa, quartam partem apicalem marginis postici attingens, versus eumdem marginem ramis plurimis obliquis emittens. Vena radialis antica dimidio basali ramis obliquis 5-6 versus marginem anticum elytri emittens, dimidio apicali margini antico valde appropinquato, haud ramoso. Venae longitudinales omnes a venis trasversis connectae. Alae extremittatem elytrorum valde superantes. Mesosternum lobis brevibus, rotundato tringularibus, metasternum lobis rotundatis. Femora omnia inferne sulcata, extus tantum spinulosa. Tibiae I et II superne rotundatae, inermes, III sulcatae, utrinque spinosae. Cerci graciles, modice incurvi, in medio vix compressi, apice acutissimi. Lamina subgenitalis parallela, margine postico subtruncato, stylis minimis instructa.

Aproxima-se de Arota Brunner, do que se distingue pelo pronoto de lobos laterais de comprimento e altura aproximadamente iguais, pela estrutura dos élitros e sobretudo pela veia radial anterior com um número muito menor de ramos oblíquos, pelas asas muito mais longas do que us élitros, com os fêmures posteriores armados de espinhos apenas no bordo externo e pelas tíbias anteriores e médias arredondadas encima. De Anaulacomera Stal, com 
o qual tem alguma afinidade, distingue-se pela estrutura dos élitros, pelos fêmures anteriores e intermédios sulcados e espinhosos e pela lâmina subgenital provida de estilos.

Tipo, a espécie seguinte.

\section{Pararota gracilis s. $n$.}

- Characteribus generis. Statura parva, structura delicatula, colore viride cum punctis rubris levissimis, sparsis, disco pronoti utrinque luteo marginato, campo tympanali partim castaneo-diluto.

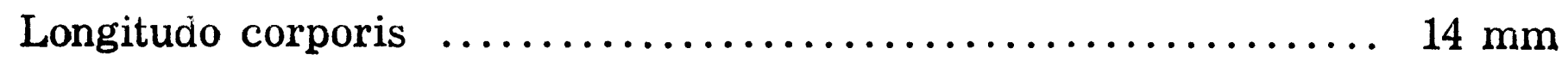

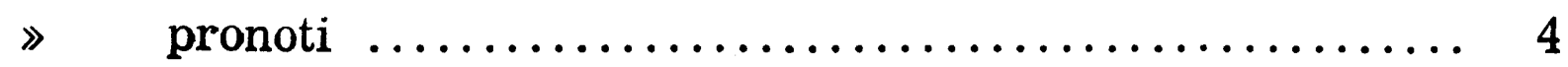

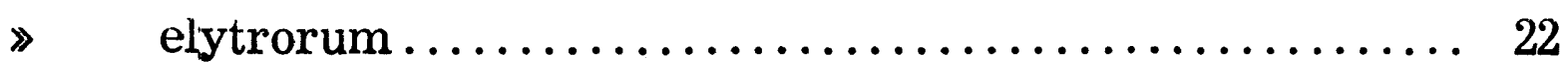

Latitudo elytrorum $\ldots \ldots \ldots \ldots \ldots \ldots \ldots \ldots \ldots \ldots \ldots \ldots \ldots \ldots \ldots \ldots$

Longitudo fem. post. ............................. 14

'l'ipo: um macho no Depart. de Zoologia da ESALQ.

Pátria: Cruzeiro do Sul, Acre.

Col.: Arnaldo Zaha, X-1972.

Doador: Dr. Amilton Ferreira.

\section{Zenirella g.n.}

Vertex convexiusculus, laevis, fastigio angusto, sulcato, apice rotundato, cum fastigio frontis haud contiguo. Frons modice convexa. Oculi magni, rotundati. Pronotum breve, margine antico vix rotundatum, margine postico regulariter rotundatum, prozona disci subconvexa, nitida, metazona subplana leniter rugulosa, obscuriore, lobis deflexis rotundatim insertis, altioribus quam longioribus, marginibus regulariter rotundatis. Elytra membranosa, parallela, apice rotundata, venis radialibus sub conjunctis, sinuosis, ramo radiali primo ante medium inserto, paulo ante medium diviso, ramis marginem elytrorum prope apicem antigentibus. Alae apicem elytrorum valde superantes. Mosesternum lobis triangularibus, metasternum rotundatis. Femora omnia subtus sulcata, I et II inermia, III spinis utrinque armata. Tibiae omnes superne sulcatae, I e II spinis nonnullis ad marginem posticum, III compluribus utrinque praeditae. Segmentum abdominale dorsale ultimum margine postico in lobos foliaceos 4 incisum, inferioribus rectangularibus, extremitate minutissime spinulosis, superioribus in partes duas divisis, parte basilare lata, superne convexa, parte terminali valde angusta, excavata, intus versus apicem sensim attenuati, modice curvi, extremitate gracillima a mucrone minutissimo terminata. Lamina subgenitalis brevis, convexa, carinata margine fortiter rotundatim marginata, stylis parvis instructa.

\section{Zenirella acreana sp. $n$.}

Gracilis, viride-lutescens. Elytra area radiali maculis nigris, longitudinaliter dispositis, area anale maculis similibus minus numerosis, ornata. Spinae pedum apice nigrae. 


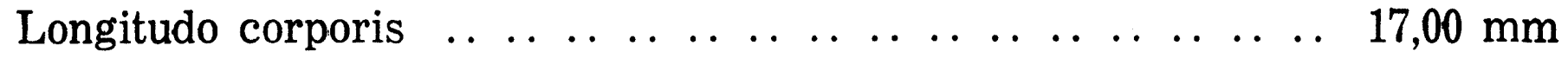

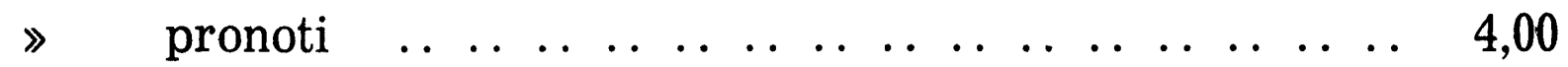

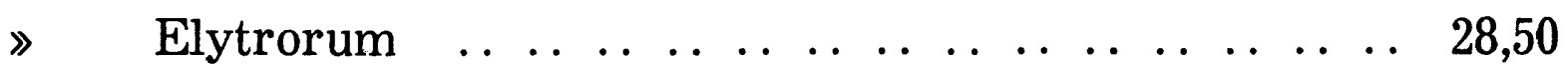

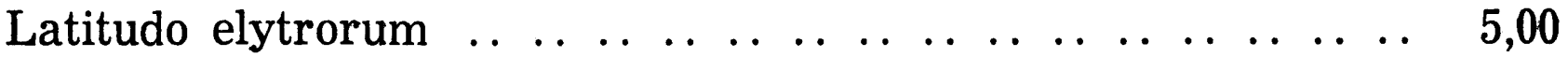

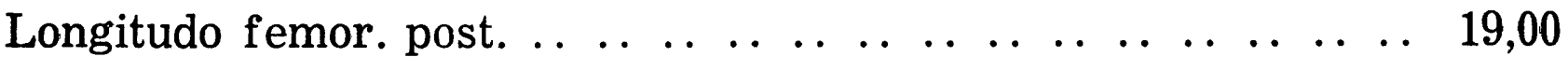

Tipo: Um macho no Dep. de Zoologia da ESALQ.

Pátria: Cruzeiro do Sul, Acre.

Col.: Arnaldo Zaha, X-1972.

Doador: Dr. Amilton Ferreira.

O presente gênero, cujo nome é dado em homenagem a Zenir Fatori, difere dos que lhe são afins, pela estrutura do último segmento abdominal.

Prosagoga ferreirai sp. $\mathrm{n}$.

- Statura mediocris, viridis. Frons subconvexa, laevis, utrinque compressa, oculis subrotundatis, paulo prominentibus. Vertex vix convexus, fastigio angusto, sulcato, a fastigio frontis remotissimo. Pronotum disco subplano, margine antico vix concavo, postico paulo convexo, ultrinque lineis duabus conjunctis, externa lutea, interna castaneo-diluta, lobis deflexis rotundatim insertis, perpendicularibus, paulo altioribus quam longioribus, parallelis, antice rectis, postice subrectis, inferne modicissime sinuosis. Elytra coreacea, nitida, margine antico subrecto, postico modice curvo, apice lato-rotundato, venis paulo expressis, venis radialibus conjunctis, modice flexuosis, ramo primo post medium oriente, ante medium furcato, ramis a venis transversis inter se, cum vena radiali postica et cum vena ulnari antica irregulariter connects, campo mediastino puncturato. Alae elytra haud superantes. Mesonotum lobis acutetriangularibus, metanotum lobis rotundatis. Femora omnia subtus sulcata, I et II inermia, III parte distali utrinqui spinis parvis nonnullis armata. Femora antica pronuto aeque longa, intermedia pronoto sat longiora. Tibiae parte basali dilatata parte apicali gracili multo breviore. Cerci cylindro-conici, fortes, modice curvi, apice haud acuminato, Styli parvi.

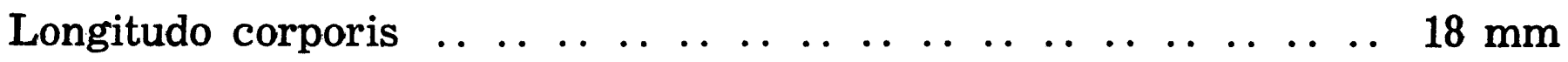

$\gg \quad$ pronoti $\ldots \begin{array}{lllllllllllllllllll} & \ldots & \ldots & \ldots & \ldots & \ldots & \ldots & \ldots & \ldots & \ldots & \ldots & \ldots & \ldots & \ldots & \ldots & \ldots & 5\end{array}$

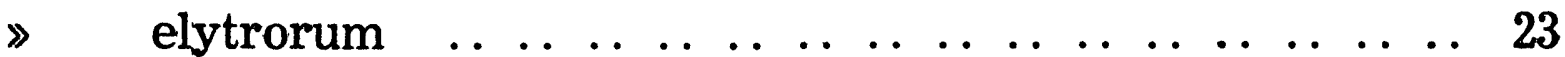

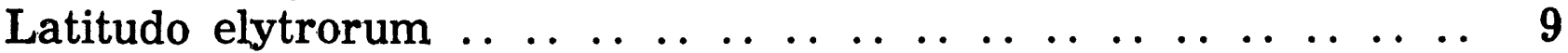

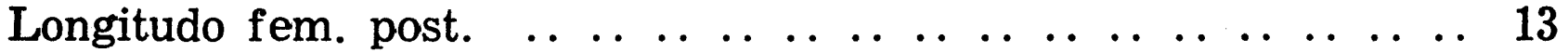

Tipo: Um macho no Dep. de Zoologia da ESALQ.

Pátria: Cruzeiro do Sul, Acre.

Col.: Arnaldo Zaha, X-1972.

Doador: Dr. Amilton Ferreira, em homenagem a quem o nome da espécie foi dado.

A presente espécie aproxima-se de Prosagoga nitidula Brunner, da qual se destingue pelos fêmures anteriores do mesmo comprimento do pronoto 
(em nitidula muito mais curtos) e pela parte dilatada das tíbias anteriores bem mais curta que a parte afilada.

\section{PSEUDOPHYLLINAE}

\section{Entacanthodes sanctaecrucis sp. $\mathrm{n}$.}

- Elytra viridia, reliquae corporis partes colore castaneo-badio. Frons lata, modice convexa, nitida. Oculi rotundati. Vertex convexiusculus, partim castaneo-obscurus, fastigio triangulari, vix concavo, angulis posticis tumescentibus, vertice curvatim elevato, leviter sulcato, scapo antennarum spina conica dimidium pedicelli vix attingente. Pronotum disco badio, ruguloso-puncturato, nitido, prozona castaneo-sordida, metazona dilutiore, castaneo-denso orlata, lobis lateralibus rotundatim insertis, viridibus, ruguloso-puncturatis, longioribus quam altioribus, angulis rotundatis, marginibus inferioribus vix sinuosis. Elytra apicem versus angustiora, extremitatem femorum posticorum valde superantia, campo tympanali castaneo-nigro, a venis crassis, ocraceocastaneis, limitato, margine postico linea lutea ornato. Femora I et III lobis genicularibus spinosis, II lobo interno tantum. Femora antica spinis 2, intermedia 4, postica 5-6, margine antico armata, spinis omnibus apice nigris. Tibiae anticae et intermediae superne inermes, posticae utrinque spinis complurimis armatae. Cerci fortes, teretes, trienti apicali angulum paene rectum designante, compresso, extus linea fortiter chitinosa, denticulata, apice conchato. Lamina subgenitalis versus extremitatem valde angustata, excavata, stylis crassis, basi conjunctis, deinde curvatim inter se remotis.

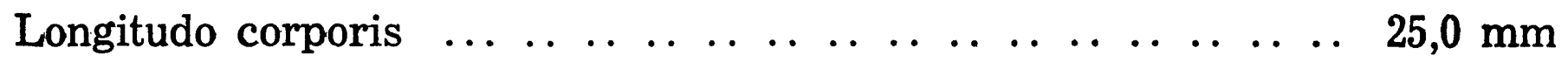

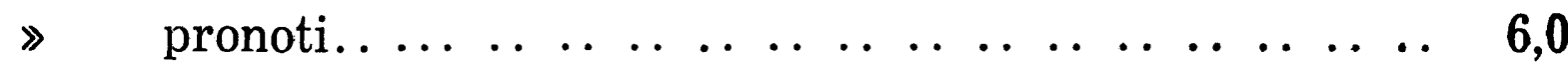

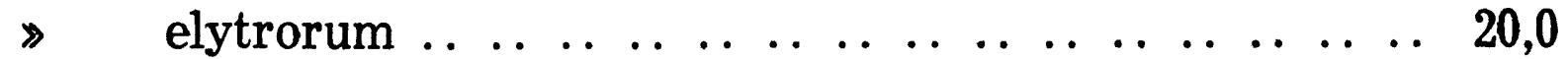

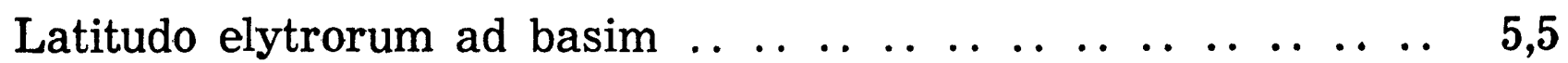

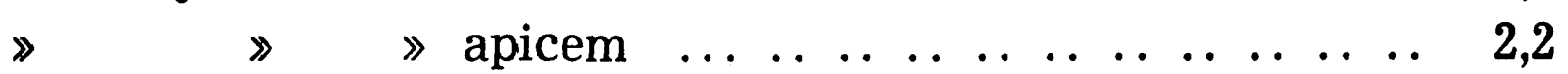

Longitudo femorum post. $\ldots \ldots \ldots \ldots \ldots$

Tipo: Um macho no Depart. de Zoologia da ESALQ.

Pátria: Santa Cruz, Acre.

Col.: Arnaldo Zaha, X-1972.

Doador: Dr. Amilton Ferreira.

Difere das espécies conhecidas pela coloração, pela forma da lâmina subgenital e dos cercos e pela ausência de espinho apenas no lobo genicular externo dos fêmures do II par. 
